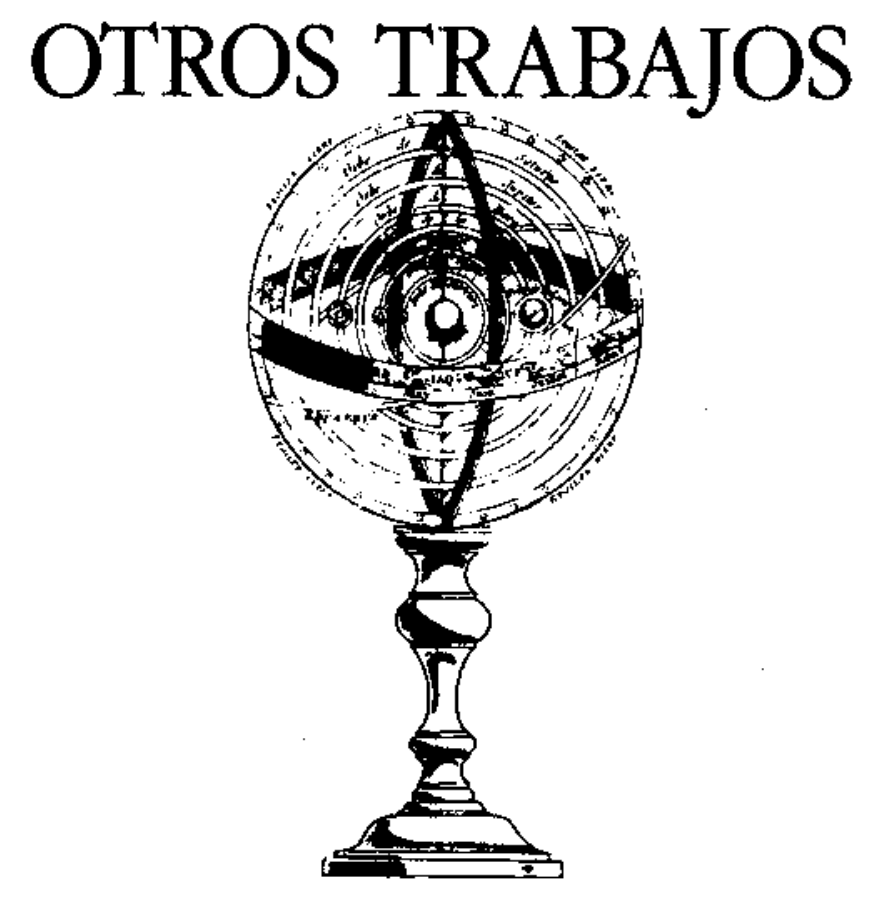

\title{
UM MAPA CONCEITUAL PARA INTERAÇŌES FUNDAMENTAIS
}

\author{
MOREIRA, M. A. \\ Instituto de Física - UFRGS. Caixa Postal 15051. 91500 Porto Alegre - RS.
}

\section{SUMMARY}

At first, the paper stresses a modern trend concerning the curriculum of high school and introductory college physics courses. According to this trend, the curriculum must be modernized by the introduction of contemporary physics topics and by teaching traditional classical physics topics from a modern point of view. Following this trend, a concept map for fundamental interactions of nature is presented focusing the topic "forces" from a unifying standpoint showing that the number of fundamental forces of nature is actually quite small. Finally, the question of contextual dependence of the meanings assigned to physical concepts is also discussed.

\section{INTRODUÇĂO}

Não é nova a crítica de que o currículo de Física ensinado nas escolas secundárias e nos cursos universitários introdutórios não incorpora a chamada Física Moderna. $O$ que se ensina, diz-se, é a Física do século passado. Essa crítica, no entanto, embora ainda válida está, de certa forma, superada. Nāo porque livros de texto mais atuais geralmente incluam alguns capítulos finais sobre tópicos como o modelo atômico de Bohr, a 
quantizaçāo da energia, o efeito fotoelétrico e outros, pois o fato de estarem nos livros não significa que sejam ensinados. A crítica está superada porque o que se pede hoje é também a inclusão de Física Contemporânea no currículo. $O$ que se convencionou chamar de Física Moderna é, a rigor, a Física do fim do século passado e início deste, enquanto que por Física Contemporânea se entende não so tópicos contemporâneos (como supercondutividade ou fusão nuclear, só para mencionar os que estāo mais em voga) mas, principalmente, uma abordagem moderna à Física.

Particularmente nos Estados Unidos, existe atualmente uma forte pressāo da parte dos físicos para que o currículo de Física da escola secundária e das disciplinas de Física Geral seja modificado no sentido de: 1) retirar alguns tópicos de áreas clássicas como a Mecânica Newtoniana, o Eletromagnetismo, a Termodinâmica e a Otica a fim de dar espaço a temas de Física Contemporânea; 2) tratar assuntos clássicos sob uma perspectiva mais atual, i.e., modelos atuais e interpretações contemporâneas.

Esse tipo de abordagem certamente vai se refletir em novos livros de texto ou em novas versōes de textos já existentes. $\hat{E}$ praticamente certo que dentro de algum tempo surgirão novos livros de Física Geral ou novas edições de textos como Halliday y Resnick (1984) ou Tipler (1984) só para citar dois muito conhecidos no Brasil. Da mesma forma, aparecerāo em breve novos livros de Física para o segundo grau, embora não cheguem ao Brasil com a mesma facilidade que os de Física Geral. Aliás, o livro de Física de maior sucesso hoje em dia na escola secundária norteamericana já segue essa orientação. Trata-se da obra Conceptual Physics, de Paul Hewitt, publicado pela Addison Wesley em 1987. Na verdade, é um pacote completo incluindo textos, manuais para o professor, manuais de laboratório, livros de testes e até vídeo-teipes. Mas existe um texto băsico que define a orientação do pacote e nesse texto observa-se pouca matemática e muita ênfase em conceitos, em interpretações microscópicas, em modelos bastantes atuais, provenientes geralmente da Física do Estado Sólido. Alguns tópicos clássicos como a Cinemática, por exemplo, são restringidos ao mínimo enquanto outros, como buracos negros e lasers, são encontrados ao longo do texto. De um modo geraI, tópicos de Física Moderna e Contemporânea permeiam o tex to ao invés de ficarem confinados aos capítulos finais. Obviamente, há muita Física Clássica, mas a abordagem é moderna e contemporânea.

A obra de Hewitt não 6 necessariamente um bom livro e não vai aqui nenhuma intenção de sugeri-la como referência, mas é um exemplo claro dos primeiros efeitos da pressão exercida nesse momento pelos físicos (e muitos professores, é verdade) norteamericanos para modificar o currículo. Mas há outros resultados desse movimento que também já estāo visíveis. A revista The Physics Teacher (TPT), por exemplo, publicou recentemente (dezembro de 1988) uma tabela, no formato de um grande cartaz, sobre partículas e interações fundamentais que é o resultado do trabalho de uma comissão de dez físicos e professores de Física, apoiado pela Associação Americana de Professores de Física e pela "National Science Foundation", e que decorre de uma conferência sobre o ensino da Física Moderna realizada no Fermilab em 1986. O objetivo central dessa comissão era o de "produzir uma tabela, em formato de cartaz, que refletisse os principais resultados obtidos nas últimas três décadas pela pesquisa em Física de Altas Energias e que fosse adequada para o uso nos cursos introdutórios de Física, tanto na escola secundária como na universidade" (op. cit., p. 556).

Essa tabela é, sem dúvida, um material instrucional da melhor qualidade, plenamente coerente com o objetivo a que se propôs a comissāo que a elaborou e provavelmente contribuirá para que os estudantes tenham uma visão bem atualizada sobre a estrutura básica da matéria. Entretanto, face à grande quantidade de informações compactadas nessa tabela, talvez ela tenha ficado um pouco densa demais. Em razão disso, me ocorreu a idéia de distribuir em dois mapas conceituais (Moreira e Buchweitz, 1987), um sobre partículas elementares e outro sobre interações fundamentais, o conteúdo dessa tabela. Creio que tais mapas podem se constituir em alternativas instrucionais vantajosas em relação à tabela por conterem menos informação e, principalmente, por terem uma organização conceitual hierárquica mais bem definida do que a que se pode chegar através de uma tabela. Por trás da suposição de que um mapa conceitual possa ter vantagens instrucionais em relaçào a uma tabela está a hipótese de que na aprendizagem significativa (em contraposição à aprendizagem memorística ou mecânica) a organizaçẫo cognitiva conceitual do aprendiz tende a uma estrutura hierárquica na qual os conceitos mais abrangentes ocupam o topo da hierarquia e, progressivamente, vão englobando conceitos menos abrangentes de modo que os conceitos bem específicos acabam por ocupar a base dessa "pirâmide conceitual" hipotética. Naturalmente, a estrutura cognitiva de um indivíduo em uma certa área de conhecimento não é estática: à medida que novas aprendizagens significativas vāo ocorrendo, essa organizaçāo conceitual hierárquica vai se modificando, se reestruturando. Essa dinamicidade é uma das características básicas da aprendizagem significativa no sentido ausubeliano (Ausubel et al. 1980).

Um corolário imediato dessa hipótese é o de que materiais instrucionais que procurem facilitar a organizaçāo cognitiva hierárquica do aprendiz têm vantagens đídáticas sobre outros que apresentam o mesmo conteúdo sem uma preocupação explícita com aprendizagem sig. nificativa. É nesse sentido que estou sugerindo mapas conceituais como vantajosos, do ponto de vista didático, em relação a tabelas.

Neste trabalho, é apresentado apenas um mapa conceitual referente à interações fundamentais da natureza. Em outro, companheiro deste, sugiro e explico um mapa conceitual sobre partículas elementares (Moreira 1989). Ambos sāo inspirados na tabela mencionada e propostos como alternativos a ela a partir de uma perspectiva didática. 


\section{UM MAPA CONCEITUAL}

À primeira vista, existem muitos tipos de forças na natureza como, por exemplo, forças elásticas, intermoleculares, interatômicas, interiônicas, de atrito, de coesão, de adesão, de viscosidade e outras. Hút também várias maneiras de classificar forças, tais como de ação à distância, de contato, dissipativas, conservativas, atrativas, repulsivas, curto alcance, longo alcance, etc.

Entretanto, na raíz de todos esses tipos e classificações estāo apenas quatro forças fundamentais, correspondentes às quatro interações fundamentais observadas na natureza: força gravitacional (interação gravitacional), força eletromagnética (interação eletromagnética), força fraca (interação fraca) e força forte (interação forte).

A força gravitacional atua em tudo, em todas as formas da matéria. Geralmente diz-se que ela atua sobre a massa das partículas, mas seria mais correto dizer que essa força age tanto sobre massa como sobre energia, uma vez que a massa pode ser considerada uma forma de energia e que existe uma relação de equivalência entre energia e massa. Assim como entre massas há uma força gravitacional, entre cargas elétricas há uma força elétrica e entre ímās, ou entre correntes elétricas, há uma força magnética. Microscopicamente, no entanto, observa-se que a força magnética entre dois imãs, por exemplo, nada mais é do que um tipo đe força elétrica entre cargas elementares em movimento no interior desses ímã̉s. Ou seja, a força magnética nāo é fundamentalmente diferente da força elétrica. Na verdade, a força elétrica e a força magnética são apenas duas instâncias, dois aspectos, de uma única força chamada força eletromagnética, assim como espaço e tempo são duas manifestações de uma única entidade física chamada espaço-tempo. (Ohanian, 1985 p. G-1.)

A força fraca atua sobre léptons e quarks ${ }^{1}$, mas é particularmente importante para neutrinos, pois a menos da força gravitacional que geralmente é insignificante entre partículas elementares, é a única força experimentada por esse tipo de partícula. Portanto, essa força tem um papel crucial na interação entre neutrinos e outras formas de matéria. A força fraca também age sobre outros léptons assim como sobre bárions e mésons, mas, nesses casos, seus efeitos são freqüentermente mascarados por efeitos muito mais intensos devidos à força eletromagnética ou à força forte. Além disso, está profundamente implicada em muitas reaçōes de decaimento (desintegraçāo) de partículas elementares (Ibid.). Por exemplo, a força fraca é responsável pelo decaimento de nêutrons. E também responsável pela radioatividade beta, ou decaimento beta, i.e., emissāo de partículas beta (elétrons ou pósitrons) por núcleos instáveis. O nome "fraca" resulta do fato de a outra força de curto alcance que atua sobre núcleons ser extremamente forte.

Cabe aqui um parêntesis: a unificação das forças (ou interaçốes) fundamentais da natureza tem sido, ao longo do tempo, uma permanente aspiração dos físicos teơri$\cos$. A interação eletromagnética é um exemplo de um avanço nesse sentido, pois a força elétrica e a força magnética são interpretadas hoje como diferentes aspectos de uma única força subjacente -a força eletromagnética que traduz essa interação. Por outro lado, Einstein, com toda sua genialidade, esforçou-se muito para chegar a uma unificaçāo das forças gravitacional e eletromagnética, mas não teve sucesso e até hoje não se chegou a essa unificação. Entretanto, novo avanço foi conseguido, há alguns anos, por $\mathrm{S}$. Weinberg, A. Salam e S. Glashow ao concluírem que a força eletromagnética e a força fraca podem ser unificadas. De acordo com sua teoria, apesar de diferenças aparentemente drásticas em suas características, as forças eletromagnética e fraca são basicamente a mesma, ou seja, sāo meramente duas instâncias de uma única força eletrofraca. (Op. cit., p. G-7.)

A força forte, por sua vez, atua entre prótons e nêutrons existertes nos núcleos atômicos assim como entre todos os bárions e mésons. As partículas elementares que interagem através da força forte são geralmente chamadas de hádrons. (Portanto, bárions e mésons são hádrons, porém léptons não o sāo.) Prótons, nêutrons e outros hádrons são constituídos de pequenas partículas fundamentais chamadas quarks. Os quarks ficam confinados dentro dos hádrons por forças mutuamente atrativas muito intensas. Essas forças entre quarks são chamadas de forças cor, mas note-se que cor é a fonte dessa força no mesmo sentido que carga elétrica é a fonte da força eletromagnética e massa/energia é a fonte da força gravitacional. Cor é uma propriedade dos quarks que nada tem a ver com o conceito de cor tal como o usamos no dia-a-dia e mesmo em outras áreas da Física. A força cor é uma força fundamental intimamente relacionada com a força forte, pois esta pode ser interpretada com um caso especial da força cor. A relação entre a força cor e a força forte é análoga à relação entre a força eletromagnética e a força intermolecular. A força entre dois átomos ou duas moléculas eletricamente neutras é uma força residual resultante de um balanço imperfeito das atrações e repulsōes entre as cargas elétricas existentes nesses átomos ou moléculas. De maneira análoga, a força forte entre duas partículas sem cor (i.e., neutras em relação à propriedade chamada cor) é uma força residual decorrente de urm balanço imperfeito das atrações e repulsões entre os quarks que constituem essas partículas. Portanto, a força forte entre hádrons (partículas sem cor) nada mais é do que manifestação de uma força mais forte e mais fundamental -a força cor- que atua entre os quarks existentes dentro de cada hádron. (Op. cit., p. G-9.)

Assim sendo, ao invés de falar em quatro forças fundamentais (gravitacional, eletromagnética, fraca e forte), como foi feito no ínicio dessa seção, pode-se dizer que há três forças fundamentais na natureza: gravitacional, eletrofraca e cor. Essas três forças aparecem com destaque na parte inferior do mapa conceitual apresentado na Figura 1. Mas se esse mapa é hierárquico e se até agora se falou praticamente só de forças fundamentais, 
figura 1

Un mapa conceitual para interaçoes fundamentais (M.A. Moreira, 1989).

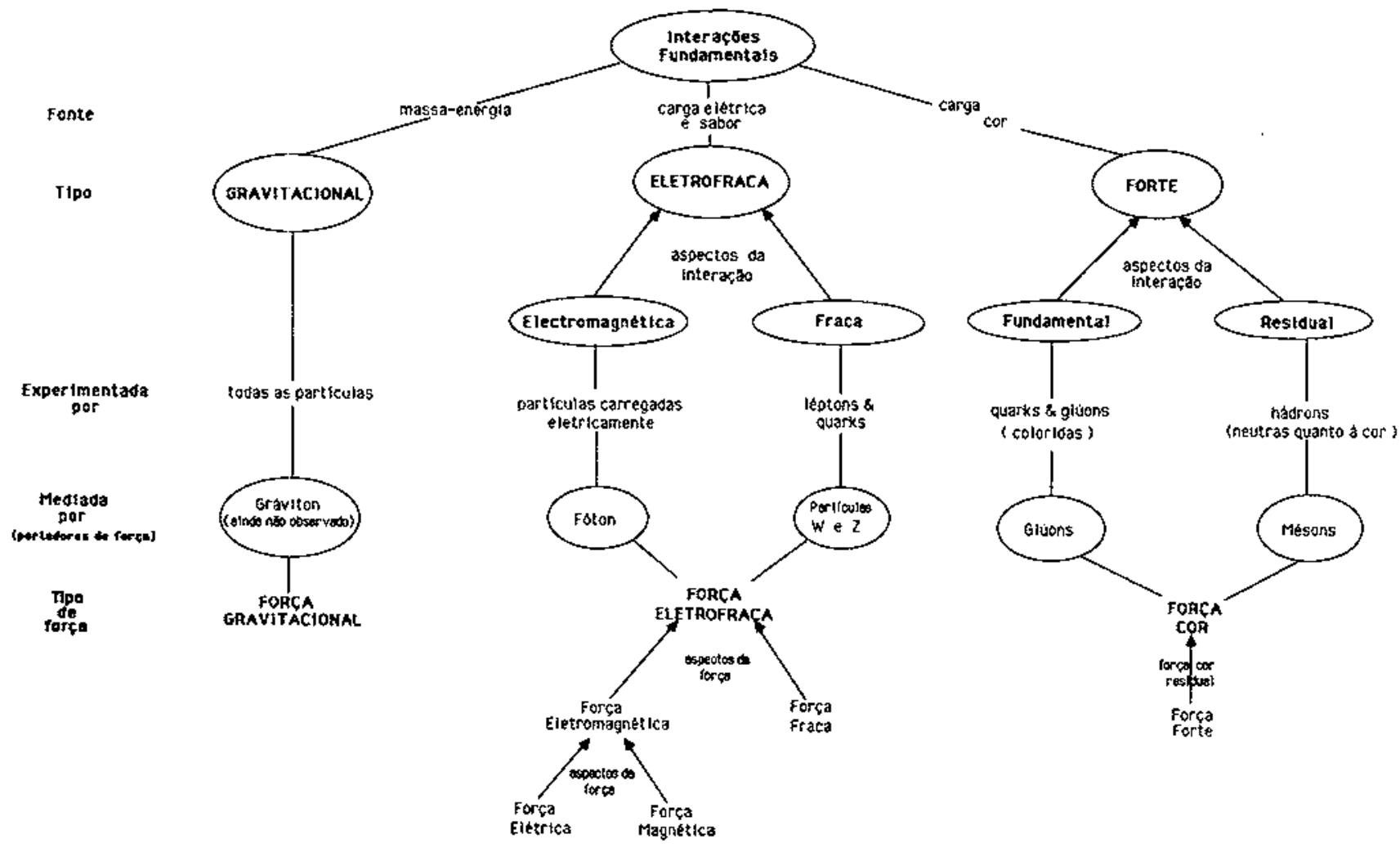

por que tais forças nāo estão na parte superior do mapa? A razāo é a seguinte:

Uma suposição básica da Física Newtoniana é a de que o movimento de uma partícula pode ser descrito pela sua posição em função do tempo. Porém, em nível microscópico, essa suposição cai por terra, pois, em conseqüência de propriedades quanto-mecânicas, a posição e a velocidade das partículas têm determinado grau de incerteza e suas trajetórias não são bem definidas. Além disso, em reações altamente energéticas entre partículas, o próprio número de partículas não é bem definido. Nessas reaçōes, partículas são criadas, destruídas e recriadas novamente. Portanto, no domínio microscópico partículas são objetos evanescentes com trajetórias incertas. Nessas circunstâncias, o conceito de força deixa de ter um significado preciso. Consequientemente, físicos de partículas preferem falar em interaçōes, ou seja, a ação de partículas sobre outras partículas. Falam, então, em interação gravitacional, interação eletromagnética, interaçôes fracas e interações fortes, ou em interaçōes gravitacional, eletrofraca e forte. Cada força existente na natureza é devida a uma dessas interaçōes fundamentais.(Op. cit., p. G-2.)

O mapa da Figura 1 apresenta tambén com destaque, na parte superior, as três interaçōes fundamentais observadas na natureza, sendo que a eletrofraca pode ser subdividida em eletromagnética ${ }^{2}$ e fraca, enquanto que a forte é usualmente diferenciada em fundamental (entre partículas com cor) e residual (entre hádrons, partícu-
Ias sem cor, mas com um balanço imperfeito em relação a essa propriedade).

Observa-se, no entanto, que o mapa da Figura 1 inclui também partículas como fótons, glưons e outras ainda năo mencionadas na explicação desse mapa. Ocorre o seguinte: cada uma das forças fundamentais da nature$\mathrm{za}$ (que podemos considerar como três ou quatro conforme considerarmos ou não as forças eletromagnética e fraca como uma só) é mediada por seu próprio campo. Há, portanto, o campo gravitacional, o campo eletromagnético, o campo fraco e o campo forte. Macroscopicamente, os campos gravitacional e eletromagnético, tão familiares no nosso dia-a-dia, são funçōes bem comportadas do espaço e do tempo (ou seja, variam suavemente no tempo e de ponto para ponto no espaço). Essas funções pođem ser calculadas através da teoria clássica de campos. Todavia, no domínio microscópico, a Física é regiđa não pela teoria clássica, mas pela teoria quântica, a qual introduz uma nova característica fundamental: a quantização da energia. Segundo essa característica, a energia armazenada nos campos nāo está distribuída de maneira contínua nesses campos; ao invés disso, a energia está concentrada nos chamados quanta de energia, i.e., pequenos pacotes ou bocados de energia. Os quanta do campo eletromagnético são os fótons, os quais são, então, os portadores da interação eletromagnética, ou da força eletromagnética. Os quanta correspondentes à interação fraca são partículas conhecidas como partículas $\mathrm{W}$ e $Z$, enquanto que partículas chamadas glúons são os quanta da inte- 
ração forte. Analogamente, supōe-se que haja também quanta da interaçäo gravitacional, seriam os grávitons. Entretanto, a crença na existência de tais partículas se apoia principalmente em considerações teóricas; grávitons nāo foram até hoje detectados e dadas as intensidades extremamente fracas do campo gravitacional em escala microscópica é pouco provável que venham a ser detectadas diretamente tāo cedo.

Em relação a essas partículas mediadoras, é interessante notar que assim como, em Química, a interação responsável pela ligação de átomos eletricamente neutros para formar compostos (a qual é claramente uma interação elétrica residual) é descrita como sendo causada pelo compartilhar de elétrons, ou pela troca de elétrons, entre átomos, a interação forte residual que liga prótons e nêutrons para formar núcleos atômicos pode ser descrita como sendo ocasionada pela troca ou pelo compartilhar de partículas coloridas, glúons e quarks, entre núcleons. A maiores distâncias entre os núcleons essa troca ocorre sob a forma de mésons, mas, naturalmente, nos dois casos, as distâncias envolvidas são extremamente pequenas. Portanto, a interpretação moderna de interaçāo entre núcleons incorpora a interpretação anterior de que apenas a troca de mésons era responsável pela formaçāo do núcleo atômico. Devido a essa interpretaçāo, em geral, quando físicos nucleares se referem à força forte, eles querem dizer a interação forte residual; porém físicos de partícula quando falam de força forte estão se referindo à força fundamental ou força cor. (TPT 1988, p.563)

\section{CONCLUSÃo}

Neste trabalho foram explorados vários aspectos instrucionais do ensino da Física. Em primeiro Iugar, foi destacada uma tendência atual que é a modernização do currículo, tanto no sentido de nele introduzir aspectos de Física Contemporânea como no de enfocar sob uma perspectiva moderna tópicos tradicionalmente abordados no $2^{a}$ grau e nas disciplinas de Física Geral. Essa tendência originalmente mais acentuada nos Estados Unidos já está chegando a outros países, inclusive da América Latina. Por exemplo, em janeiro de 1990 será realizada em Cuba a "Primeira Escola sobre Ensino da Física Moderna", na qual um dos temas básicos é a introdução de aspectos contemporâneos nas disciplinas de Física Geral.

Nessa linha, foi apresentado um mapa conceitual para interaçōes fundamentais na natureza. Nesse mapa o tópico "forças" foi abordado de um ponto de vista unificador mostrando que, a rigor, é bastante reduzido o número de forças fundamentais da natureza. Foi também destacado que, normalmente, pelo menos no domínio subatômico, é preferível falar em interações do que em forças. Quer dizer, força é um conceito que, embora seja extremamente usado no domínio da Mecânica Newtoniana, perde significados na Física das
Partículas Elementares. O mapa inclui ainda o conceito de partículas mediadoras como fótons (mediadoras da interação eletromagnética), partículas $\mathrm{We} \mathrm{Z}$ (interação fraca) e glúons (interação forte). Naturalmente, esse conceito conduz à suposição de que, segundo o modelo vigente, deve existir uma partícula mediadora da interaçāo gravitacional. Essa partícula seria o gráviton, mas ainda não foi detectada.

Esta é, sem dúvida, uma visão contemporânea do assunto, a qual provavelmente sofrerá modificaçōes decorrentes da produção de novos conhecimentos nessa área. Naturalmente, essa visão pode nāo ser apropriada em determinadas situaçōes instrucionais, mas traz para o professor pelo menos três importantes implicações para o ensino da Física:

1. Um mesmo conceito físico pode ser usado em várias situaçôes, inclusive com um nome um pouco diferente. No caso de forças, por exemplo, nāo se deve dar ao aluno a idéia de que cada uma das forças que aparecem no estudo de certos fenômenos físicos é distinta das demais. Como vimos, no fundo, são manifestações de umas poucas forças fundamentais. O importante, do ponto de vista instrucional, é focalizar o conceito em si e destacar que ele pode aparecer com roupagem diferente conforme o fenômeno que está sendo analisado. Outro exemplo, é o conceito de onda: fala-se em onda transversal e onda longitudinal ou em onda sonora, onda Iuminosa, onda eletromagnética, etc. É claro que é importante distinguir entre tais classificações, mas é talvez mais importante o aluno ficar com uma idéia clara, bem diferenciada e estável sobre o que é uma onda, independente de sua natureza. O conceito de energia serve também como um bom exemplo e, nesse caso, pode-se ir além de simplesmente deixar claro que energia cinética, potencial, elástica, elétrica, nuclear e outras sảo apenas formas de energia. Pode-se mostrar que conceitos aparentemente muito diferentes, como massa e calor, são também formas de energia. É preciso não tratar a Física como uma ciência catalográfica, cheia de conceitos diferentes que devem ser classificados e memorizados. Assim como as fórmulas que os alunos tanto abominam são, a rigor, variações de algumas equações básicas, muitos dos conceitos usados em Física são instâncias de alguns poucos conceitos-chave.

2. Conceitos têm domínios de validade. Como foi visto, no campo das partículas elementares, o conceito de interaçāo tem mais significado do que o conceito de força. O que define um conceito são os signifícados atribuídos a ele e que sāo compartilhados por uma determinada comunidade de usuários. No caso da Física, essa comunidade é representada por físicos, professores e estudantes de Física. Significados, por sua vez, são contextuais, i.e., dependem do contexto. Portanto, ao invés de dizer que conceitos têm domínio de validade, poder-se-ia dizer que os significados é que são válidos apenas dentro de certos domínios. Por exemplo, o significado de massa como uma característica constante de um corpo só é válido para velocidades não relativísticas. $O$ conceito de potencial, tāo útil na eletrostática, não tem significado na magnetostática. 
Certamente há outros exemplos, mas o importante aqui não é chamar atenção para este ou aquele conceito, mas para o fato de que qualquer conceito físico deve ser ensinado como algo cujos significados dependem do contex to onde sāo empregados. Conceitos são extremamente importantes na Física, mas não são absolutos.

3. A Física faz uso de modelos, os quais permitem organizar o que foi observado e prever novas observaçöes. O mapa conceitual da Figural reflete um modelo ao qual chegaram os físicos para explicar resultados experimentais, mas, ao mesmo tempo, esse modelo tem Iugar para resultados ainda não obtidos, como é o caso do gráviton. É possível distinguir entre modelos e teorias se atribuirmos a estas uma maior abrangência $e$, talvez, maior estabilidade. Mas, em última análise, teorias são também modelos e sua estabilidade é relativa. Quer dizer, modelos não são definitivos nem únicos. É possível explicar determinadas observaçōes, certos resultados experimentais, através de diferentes modelos. Naturalmente, uns são mais adequados do que outros, no sentido de terem maior poder explicativo e permitirem uma "melhor ordenaçāo" das observações. No caso das partículas elementares, o modelo atual, chamado modelo padrão, é o melhor modelo ao qual chegaram os físicos de partículas até o momento. Mas 6 um erro pensar que esse modelo é definitivo; prova disso é que há quem suponha a existência de uma quinta força fundamental da natureza, ou seja existiria uma outra interação básica (French 1986). ${ }^{3}$ Analoga-

\section{AGRADECIMENTO}

Agradeço à Professora Eliane Angela Veit pela análise crítica do presente trabalho.

(1) É possível classificar o grande número de partículas elementares até hoje detectadas (cerca de 300 ) em três grandes grupos: léptons, bárions e mésons, sendo que os dois últimos grupos podem ser reagrupados e designados coletivamente por hádrons. $O$ elétron é o lépton mais familiar; múons e neutrinos também são léptons. Prótons e nêutrons são os bárions mais conhecidos. Léptons parecem ser verdadeiramente elementares no sentido de não possuirem estrutura interna. Por outro lado, parece haver já evidência convincente de que prótons, nêutrons e outras partículas elementares sāo constituídas de partículas ainda menores chamadas quarks. Segundo o modelo vigente, quarks não podem ser detectados isoladamente; ficam confinados no interior de partículas compostas (hádrons).

(2) A interação eletromagnética, por sua vez, pode ser diferenciada em elétrica e magnética. Tal diferenciação não consta no mapa da Figura $\mathrm{I}$ apenas para não introduzir mais mente, é um erro didático ensinar outras teorias e modelos físicos como definitivos, prontos, acabados. A Física, embora uma das grandes heranças culturais da humanidade, não pode ser ensinada como se fosse imutável. Justamente ao contrário: a Física é uma ciência dinâmica, em construção permanente.

Outro aspecto instrucional explorado neste trabalhoé o mapa conceitual como recurso didático, o qual não retomarei aqui por acreditar que suas potencialidades são evidentes e porque quero deixar a ênfase do trabalho na questāo da modernizaçāo do currículo. Nessa perspectiva, $O$ assunto interações fundamentais passa também a ser secundário. O importante é destacar a tendência atual de modernizar o ensino da Física nāo só no sentido de incluir tópicos de Física Contemporânea no currículo, mas também de abordar a Física de uma "maneira moderna". A tendência é chamar a atençăo de professores e autores de livros para que deixem de apresentar a Física como uma grande coleção de formulas baseadas em teorias, princípios e leis que sāo verdades absolutas. Enquanto isso continuar ocorrendo, enquanto se continuar ignorando a contextualidade dos conceitos e enquanto se permanecer ensinando Física sob uma ênfase curricular (Moreira e Axt 1986) que a apresenta como uma ciência de explicações corretas para fenômenos da natureza, nāo será surpresa se os alunos continuarem a tentar aprender Física através da memorizaçāo de fórmulas e definições e continuarem a não gostar de Física. um subnivel vertical na hierarquia conceitual nele representada. Em um mapa conceitual há sempre um compromisso entre completeza e complexidade.

(3) Segundo essa hipotese, além das quatro forças fundamentais da natureza (gravitacional, eletromagnética, fraca e forte) haveria evidências de uma quinta força que, por ser de Iongo alcance, teria seu raio de açāo superposto ao da força gravitacional. A intensidade dessa força dependeria do número total de nêtutrons e prótons das massas interagentes, não sendo estritamente proporcional a massa inercial; sua intensidade variaria ligeiramente com a composição química. Portanto, a razão peso/massa para corpos atraídos pela Terra näo seria precisamente a mesma para diferentes materiais. As variações seriam extremamente pequenas -da ordem de uma parte em $10^{8}-$ mas as implicaçōes teóricas seriam profundas. (French 1986, p. 270) 


\section{REFERENCIAS BIBLIOGRÁFICAS}

AUSUBEL, D. P., NOVAK, J. D. e HANESIAN, H., 1980. Psicologia educacional. (Interamericana: Rio de Janeiro).

BEISER, A., 1982. Physics. (3". ed.). (Menlo Park, CA, The Benjamin/Cummings Publishing Co.).

FRENCH, A.P., 1986. Is there a fifth fundamental force?, The Physics Teacher, 24(5), pp. 270-273.

Fundamental Particles and Interactions Chart Committee, 1988. Fundamental particles and interactions - a wall chart of modern physics, The Physics Teacher, 26(9), pp. 556565.

HALLIDAY, D. e RESNICK, R., 1984. Física. (4 ${ }^{\text {s }}$ ed.), (Livros Técnicos e Científicos: Rio de Janeiro).

HEWITT, P., 1987. Conceptual Physics. (Addison Wesley: Reading, MA).
MOREIRA, M.A. e AXT. R., 1986, O livro didático como veículo de ênfases curriculares no ensino de Física, Revis. ta de Ensino de Física, 8(1), pp. 33-48.

MOREIRA, M. A. e BUCHWEITZ, 1987. Mapas conceituais - instrumentos didádicos, de avaliação e de anátise de cu. rriculo. (Editora Moraes: São Paulo).

MOREIRA, M. A., 1989. Um mapa conceitual para partículas elementares. (Manuscrito submetido à publicação).

OHANIAN, H. C., 1985. Physics. (W. W. Norton \& Company: New York).

TIPLER, P. A., 1984. Física. ( $2^{z}$ ed.). (Guanabara Dois: Rio de Janeiro). 